American Journal of Pharmaceutical Education 2016; 80 (10) Article 166.

\title{
RESEARCH
}

\section{Integration of Basic and Clinical Science Courses in US PharmD Programs}

\author{
Mohammed A. Islam, PhD, ${ }^{\text {a }}$ Rahmat M. Talukder, PhD, ${ }^{\mathrm{b}}$ Reza Taheri, PharmD, MBA, \\ Nicholas Blanchard, PharmD, MEd ${ }^{\mathrm{a}, \mathrm{c}}$ \\ ${ }^{a}$ West Coast University School of Pharmacy, Los Angeles, California \\ ${ }^{\mathrm{b}}$ Ben and Maytee Fisch College of Pharmacy, the University of Texas at Tyler, Tyler, Texas \\ ${ }^{c}$ Affiliation at time of study. Dr. Blanchard's current affiliation is with Wingate University School of Pharmacy, Wingate, \\ North Carolina.
}

Submitted August 24, 2015; accepted November 1, 2015; published December 25, 2016.

Objective. To determine the current status of and faculty perceptions regarding integration of basic and clinical science courses in US pharmacy programs.

Methods. A 25-item survey instrument was developed and distributed to 132 doctor of pharmacy (PharmD) programs. Survey data were analyzed using Mann-Whitney U test or Kruskal-Wallis test. Thematic analysis of text-based comments was performed using the constant comparison method.

Results. One hundred twelve programs responded for a response rate of $85 \%$. Seventy-eight (70\%) offered integrated basic and clinical science courses. The types of integration included: full integration with merging disciplinary contents $(n=25)$, coordinated delivery of disciplinary contents $(n=50)$, and standalone courses with integrated laboratory $(n=3)$. Faculty perceptions of course integration were positive. Themes that emerged from text-based comments included positive learning experiences as well as the challenges, opportunities, and skepticism associated with course integration.

Conclusion. The results suggest wide variations in the design and implementation of integrated courses among US pharmacy programs. Faculty training and buy-in play a significant role in successful implementation of curricular integration.

Keywords: pharmacy education, integration, basic sciences, clinical sciences, curriculum

\section{INTRODUCTION}

There is an increasing recognition among medical and other health science educators that traditional disciplinary education does not conform to the current demands of interdisciplinary learning and practice. ${ }^{1,2}$ The isolated disciplinary model of education lacks connectedness among different learning experiences. ${ }^{3}$ For these reasons, curricular integration has emerged as an important strategy in healthcare education. ${ }^{2,4-6}$ Notably, the integration of basic sciences with clinical sciences has been a focal point in medical education reform. A 2010 medical education study of 148 medical schools in the United States and Canada found that $82 \%$ of the 128 reporting schools had adopted curricular integration or were in the process of adopting integration as a central characteristic of their curricula. ${ }^{5}$ North American dental schools also have begun to integrate basic and clinical sciences. ${ }^{6} \mathrm{~A}$ 2009 survey of US and Canadian dental schools reported

Corresponding Author: Mohammed A. Islam, PhD, West Coast University School of Pharmacy, 590 N. Vermont Ave., Los Angeles, CA 90004. Tel: 818-232-4124. Fax: 323-6610935. E-mail: mislam@westcoastuniversity.edu that $49 \%$ of the reporting schools had adopted interdisciplinary courses in their curricula. ${ }^{6}$ Similar to medicine and dentistry, the Accreditation Council for Pharmacy Education (ACPE) Standards 2016 also support a trend towards curricular integration in professional pharmacy programs. ${ }^{7}$ ACPE standards expect that graduates develop, integrate, and apply foundational science knowledge to solve clinical problems. ${ }^{7}$

The literature includes an increasing number of reports on integration at the levels of topics, modules, courses, and entire curriculum in pharmacy programs. ${ }^{8-14}$ Stewart and colleagues reported that integration of specific pharmaceutics and pharmacy practice course concepts improved students' learning and application of concepts. ${ }^{9}$ Kullgreen and colleagues described an integrated course focusing on pain and palliative care; this course was developed by linking concepts of pathophysiology, pharmacology, medicinal chemistry, formulations and drug delivery, and pain management. ${ }^{10}$ Moreover, Kolluru and colleagues discussed the integration of basic and clinical sciences in a multi-instructor, team-based active-learning exercise in a depression module of a pharmacotherapy course. ${ }^{11}$ The integration of didactic and experiential 


\section{American Journal of Pharmaceutical Education 2016; 80 (10) Article 166.}

education has also been described through Learning Bridge assignments by Karimi and colleagues. ${ }^{12}$ These assignments were designed and implemented by a team of faculty members from basic, clinical, and social administrative sciences where pharmaceutical sciences concepts were applied in the introductory pharmacy practice experiences (IPPEs). This approach was reported to promote students' interaction with their preceptors as well as their development of active-learning and self-directed learning skills. ${ }^{12}$ In addition to these examples, pharmacy programs with full integration of biomedical, pharmaceutical, social/ behavioral/administrative, and clinical sciences are also being developed. ${ }^{14}$

The benefits of curricular integration have been presented in the literature. In an integrated approach, students learn faster and more comprehensively, as they observe the relevance and connections among diverse concepts or subject areas. ${ }^{15,16}$ Furthermore, integration helps learners develop problem-solving skills and apply learned experiences in real-life situations. ${ }^{17,18}$ While the impetus for curricular integration is evident, the implementation of integration remains a significant challenge. ${ }^{19,20}$ Isolated reports of integration at the course level or across segments of the curriculum have been described; however, the level and extent of curricular integration across colleges/school of pharmacy remain unclear. The purpose of this study is to determine the current status of basic and clinical science integration in US colleges and schools of pharmacy. Both qualitative and quantitative data on course integration as well as faculty perception of the design, implementation, and challenges of integrated courses are presented.

\section{METHODS}

A survey instrument was developed to collect quantitative and qualitative information on the integration of basic and clinical science courses in US doctor of pharmacy (PharmD) programs. The survey instrument was divided into four sections and included 25 items. The first section of the survey focused on faculty members' general perceptions regarding curricular integration. The second section asked whether their school or college was offering integrated courses, and about the design and implementation of integrated basic and clinical science courses. The third section of the survey solicited respondents' input regarding barriers and challenges encountered in the implementation of integrated courses. The last section collected demographic information on the faculty members.

Survey items were formulated based on our current understanding of curricular integration literature. As a pretesting process, the survey was reviewed by two independent pharmacy faculty members who did not participate in the study. The survey instrument was revised based on their feedback regarding the clarity of questions and whether survey items adequately addressed the study objectives. In an attempt to minimize survey fatigue, skip logic was employed; this approach directed respondents to different paths in the survey based on their responses.

An electronic hyperlink to the survey instrument was emailed to faculty members at all 132 accredited and candidate-status PharmD programs in the United States and its territories using the American Association of Colleges of Pharmacy (AACP) curriculum special interest group (Curriculum SIG) email distribution list. SurveyMonkey (SurveyMonkey, Inc., Portland, OR) was used to collect responses. The survey instrument was configured to track each response from a college or school based on the respondents' email address. The survey instrument was initially sent on August 28, 2014, followed by two subsequent reminders sent four weeks apart. The survey response window was closed on November 22, 2014. A cover letter accompanied the survey instrument, explaining the purpose of the survey along with assurances that participation was voluntary and participants' identity would remain confidential. To ensure confidentiality, all files were password protected and stored in a passwordprotected stationary computer in a locked office.

Survey responses were downloaded into Microsoft Excel. If multiple individuals from the same institution responded to questions, data were not combined when conflicting answers were chosen for nonperception questions. To account for these isolated instances, the answer was selected based on the respondent individual's position, with preference given to faculty members considered most likely to have the best understanding of the curriculum (ie, years of experience and type of position). Data for all perception and experience-based questions were combined.

Items related to the perception of faculty on various aspects of integration were self-reported on a 5-point Likert scale, ranging from $1=$ strongly disagree to $5=$ strongly agree. Mann-Whitney U test or Kruskal-Wallis test (SigmaPlot, version 3, Systat Software Inc, San Jose, California) was used to assess significance among independent variables (type of institution, years of existence of the program) and the dependent variables (respondents' level of agreement). Text-based comments were collated and thematic analysis of the content was performed using the constant comparison method. ${ }^{21}$ Initial coding and theme generation were performed manually by highlighting texts and making notes; both tasks were performed independently by two investigators. An iterative review process involving another investigator was 


\section{American Journal of Pharmaceutical Education 2016; 80 (10) Article 166.}

used to further clarify themes. Geographic locations of schools and colleges of pharmacy were collected based on 9 divisions as defined by the US Census Bureau. ${ }^{22}$ This study was deemed exempt by the West Coast University Institutional Review Board.

\section{RESULTS}

One hundred twelve of 132 ACPE candidate status and accredited US PharmD programs responded to the survey, yielding a response rate of $85 \%$. Demographic information for the programs and faculty respondents is shown in Table 1. The percentages of responding public and private institutions were $44 \%$ and $56 \%$, respectively. Seventy percent of programs adopted a semester system, while quarter and block systems were adopted by $20 \%$ and $10 \%$, respectively. The class sizes for responding institutions varied with $49 \%$ reporting a class size of $51-100$; $23 \%$, a class size of $101-150$, and $19 \%$, a class size of 151-200. Of the 184 faculty members who responded to the survey, $50 \%$ were pharmacy practice or clinical faculty members, while the remaining half included basic biomedical, pharmaceutical, and social and administrative sciences faculty members. Over $50 \%$ of the respondents indicated having 10 years or more of academic experience in pharmacy.

Out of the 112 colleges and schools participating, 78 $(70 \%)$ offer some form of integration between basic and clinical science courses. Several types of course combinations were identified in basic and clinical science integration: physiology/pathophysiology, medicinal chemistry, pharmacology, and therapeutics $(\mathrm{n}=32)$; medicinal chemistry, pharmacology, and therapeutics $(\mathrm{n}=26)$; physiology/ pathophysiology, pharmacology, and therapeutics $(n=4)$; pathophysiology and therapeutics $(n=4)$; and all science courses $(n=2)$. Thirteen colleges and schools $(12 \%)$ had only integrated selected basic science courses. Twenty colleges and schools (18\%) reported not offering any integrated course.

Figure 1 presents the type of integration adopted by colleges and schools of pharmacy to deliver basic and clinical science courses. Out of 78 programs indicating integration, 25 programs (32\%) offered courses with full integration between basic and clinical science contents. In these fully intergrated courses, the contents were merged and presented together by faculty members from different disciplines who linked basic and clinical sciences concepts and their relevance to one another. This high-level integration was reported by faculty members at $22 \%$ of the 112 programs that participated in the study. At 50 (64\%) programs, disciplinary contents were presented in a coordinated and sequential manner. In the 19 programs designated as using the coordinated approach, course delivery was
Table 1. Demographic Information of the Programs and Faculty Respondents $(\mathrm{N}=126)$

\begin{tabular}{|c|c|}
\hline Characteristics of Schools and Colleges (n) & No. $(\%)$ \\
\hline \multicolumn{2}{|l|}{ Type of institution (112) } \\
\hline Public & $49(43.7)$ \\
\hline Private & $63(56.3)$ \\
\hline \multicolumn{2}{|l|}{ Time in existence (93) } \\
\hline$\leq 5$ years & $20(21.5)$ \\
\hline $6-10$ years & $22(23.6)$ \\
\hline $11-20$ years & $13(14.0)$ \\
\hline$>20$ years & $38(41.3)$ \\
\hline \multicolumn{2}{|l|}{ Students in each graduating class (98) } \\
\hline$<50$ & $4(4.0)$ \\
\hline $51-100$ & $48(49.0)$ \\
\hline $101-150$ & $23(23.4)$ \\
\hline $151-200$ & $19(19.3)$ \\
\hline$>200$ & $4(4.0)$ \\
\hline \multicolumn{2}{|l|}{ Regional distribution (112) } \\
\hline Northeast & $18(16.0)$ \\
\hline Southeast & $11(9.8)$ \\
\hline Middle Atlantic & $13(11.6)$ \\
\hline Mountain & $13(11.6)$ \\
\hline New England & $9(8.0)$ \\
\hline Pacific & $9(8.0)$ \\
\hline South Atlantic & $18(16.0)$ \\
\hline Northwest & $9(8.0)$ \\
\hline Southwest & $11(9.8)$ \\
\hline Other & $1(0.1)$ \\
\hline \multicolumn{2}{|l|}{ Faculty (n) } \\
\hline \multicolumn{2}{|l|}{ Institution type (184) } \\
\hline Public & $78(42.0)$ \\
\hline Private & $106(58.0)$ \\
\hline \multicolumn{2}{|l|}{ Experience in pharmacy school/college (144) } \\
\hline$<1$ year & $2(1.4)$ \\
\hline $1-2$ years & $7(4.9)$ \\
\hline $3-5$ years & $23(16.1)$ \\
\hline $6-10$ years & $35(24.5)$ \\
\hline$>10$ years & $78(53.1)$ \\
\hline \multicolumn{2}{|l|}{ Discipline (151) } \\
\hline Physiology & $2(8.0)$ \\
\hline Medicinal chemistry & $12(8.0)$ \\
\hline Pharmacology/Toxicology & $24(15.9)$ \\
\hline Biochemistry & $3(2.0)$ \\
\hline Microbiology/Immunology & $2(1.3)$ \\
\hline Pharmaceutics & $11(7.3)$ \\
\hline Pharmacotherapy & $75(49.7)$ \\
\hline Social and Administrative Sciences & $12(7.9)$ \\
\hline
\end{tabular}

followed by integrated case discussions involving both basic and clinical science aspects. Three programs indicated that they offered isolated, standalone courses in medicinal chemistry, pharmacology, and therapeutics; however, the concepts for these were integrated in pharmaceutical care/ clinical laboratory sessions. 


\section{American Journal of Pharmaceutical Education 2016; 80 (10) Article 166.}

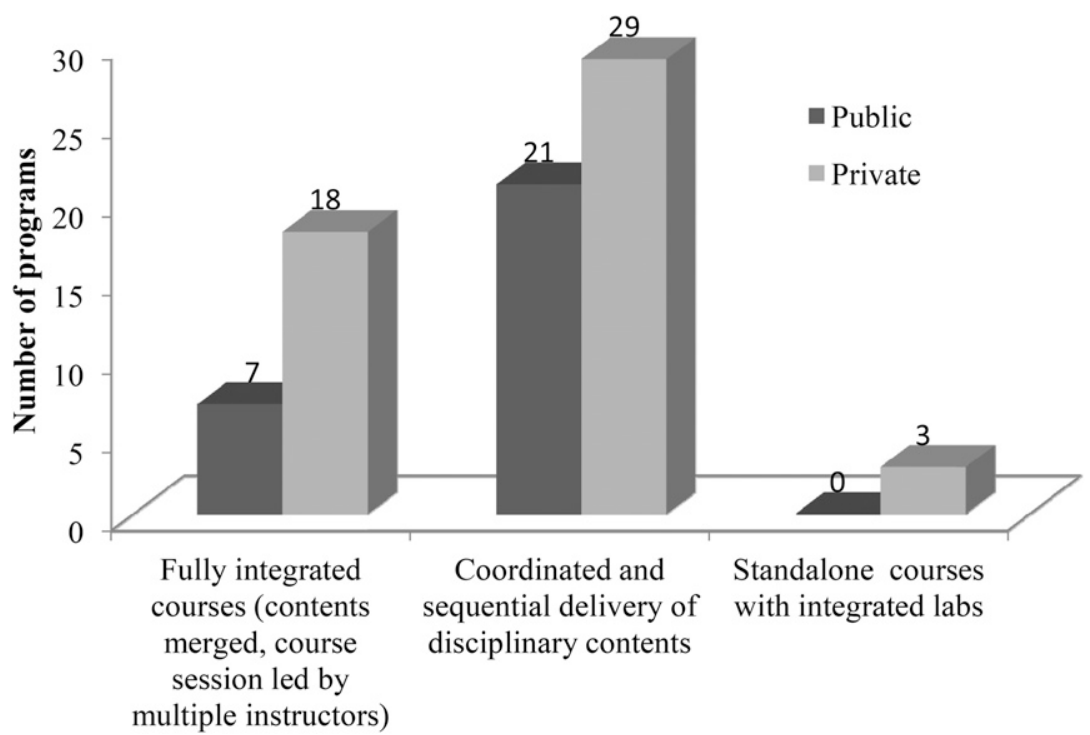

Figure 1. Different forms of integration among basic and clinical science courses

Faculty members at 27 colleges and schools of pharmacy responded to the survey item asking them to break down the contact hours for each component of integrated courses. The distribution of contact hour for integrated courses combining physiology, medicinal chemistry, pharmacology, and pharmacotherapy was: pharmacotherapy, 50\%; pharmacology, 20\%; physiology/pathophysiology, $18 \%$; and medicinal chemistry, $12 \%$. Fifty-eight colleges and schools indicated that their integrated courses were taught as a series of organ system/disease state modules. Figure 2 shows the pedagogical methods employed in delivering integrated courses. The use of multiple pedagogical strategies was common in programs. The most commonly employed course delivery methods included: lecture $(97 \%)$, case-based instruction/learning $(90 \%)$, and discussion/recitation (67\%). Problem-based and team-based learning in combination with other methods were identified by $55 \%$ and $50 \%$ respondents, respectively. Fifty-one percent used self-directed learning. Additional strategies used included journal club, simulation, and the flipped classroom model. Another important commonality in the curricular delivery of integrated courses was the involvement of multiple faculty members in a single classroom session (47\%). Only $44 \%$ of the responding programs indicated that course materials (PowerPoint slides, cases) and assessment tools were developed collaboratively.

Faculty members also were asked about their general perceptions of the impact of curricular integration (Figure -3). Eighty-two percent of respondents agreed/strongly agreed that curricular integration resulted in learning experiences that were more relevant and engaging while facilitating higher-order learning. Almost $90 \%$ of the respondents agreed/strongly agreed with the statement that "integration of basic and clinical science courses in the PharmD curriculum forms a framework of student learning which allows integration of knowledge, skills, and attitudes to offer effective patient care." Respondents were asked whether application, analysis, synthesis, and evaluation capabilities were best achieved in an interdisciplinary integrated course. The majority of respondents $(61 \%)$ were in agreement with this

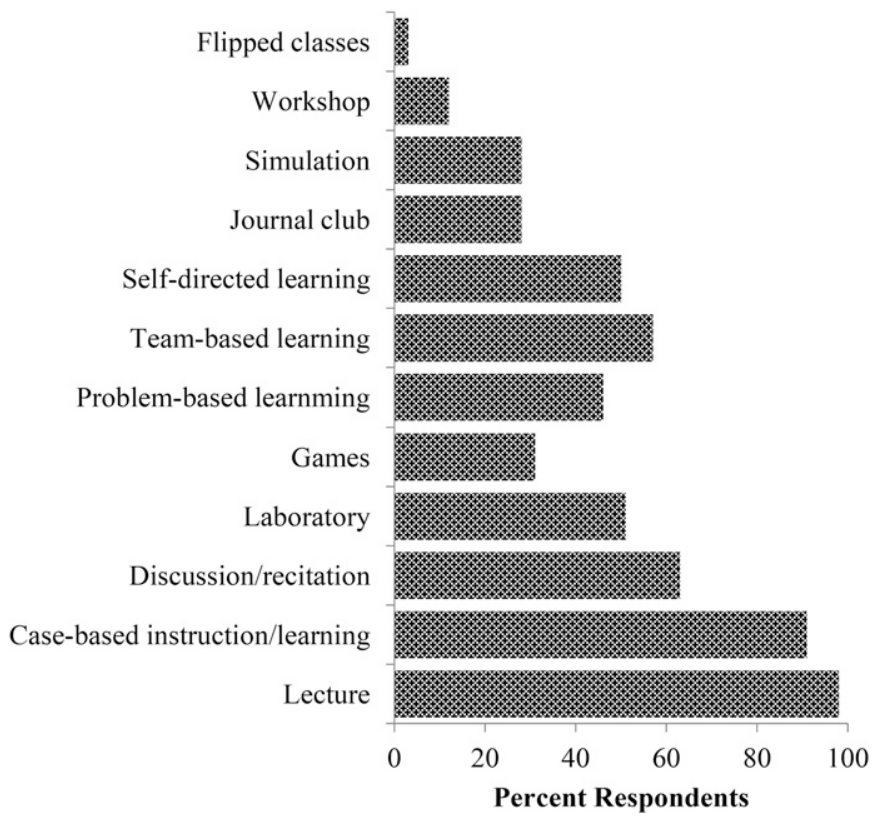

Figure 2. Pedagogical methods employed in delivering integrated courses 


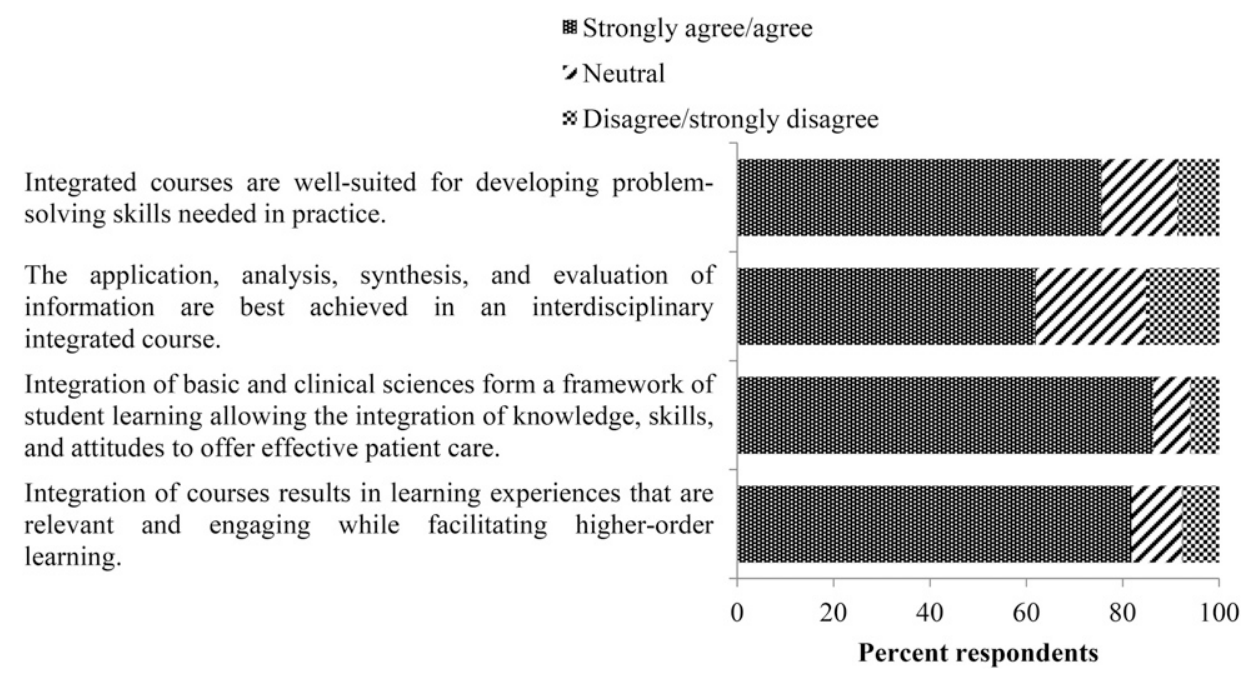

Figure 3. Faculty's general perceptions of the impact of curricular integration

statement. Seventy-six percent $(76 \%)$ of the respondents agreed or strongly agreed that integrated courses helped to develop problem-solving skills needed in pharmacy practice.

Respondents who indicated that integration of basic and clinical science courses are in place in their programs were asked to complete questionnaires on the development and implementation of integrated courses (Figure 4). Seventy-six percent of respondents agreed or strongly agreed that the planning and design of integrated courses involved collaboration among basic and clinical science faculty members. However, only $51 \%$ of the respondents agreed or strongly agreed with the statements that "all instructors (not just the course coordinator/director) are involved in the sequencing of course contents and their contact hour distribution." Seventy-five percent of the respondents indicated that contact hour distribution was adequate to ensure depth and breadth of each component of the integrated course. As shown in Table 2, there were no significant differences in response rates between public and private institutions for survey items on the value and impact of integration and development and implementation of integrated courses.

The pharmacy programs offering integrated courses indicated having multiple challenges and barriers to the implementation of integrated curriculum (Figure 5). Notably, the largest challenge identified was the high demand on faculty workload as indicated by $81 \%$ of the respondents. Additional major barriers and challenges

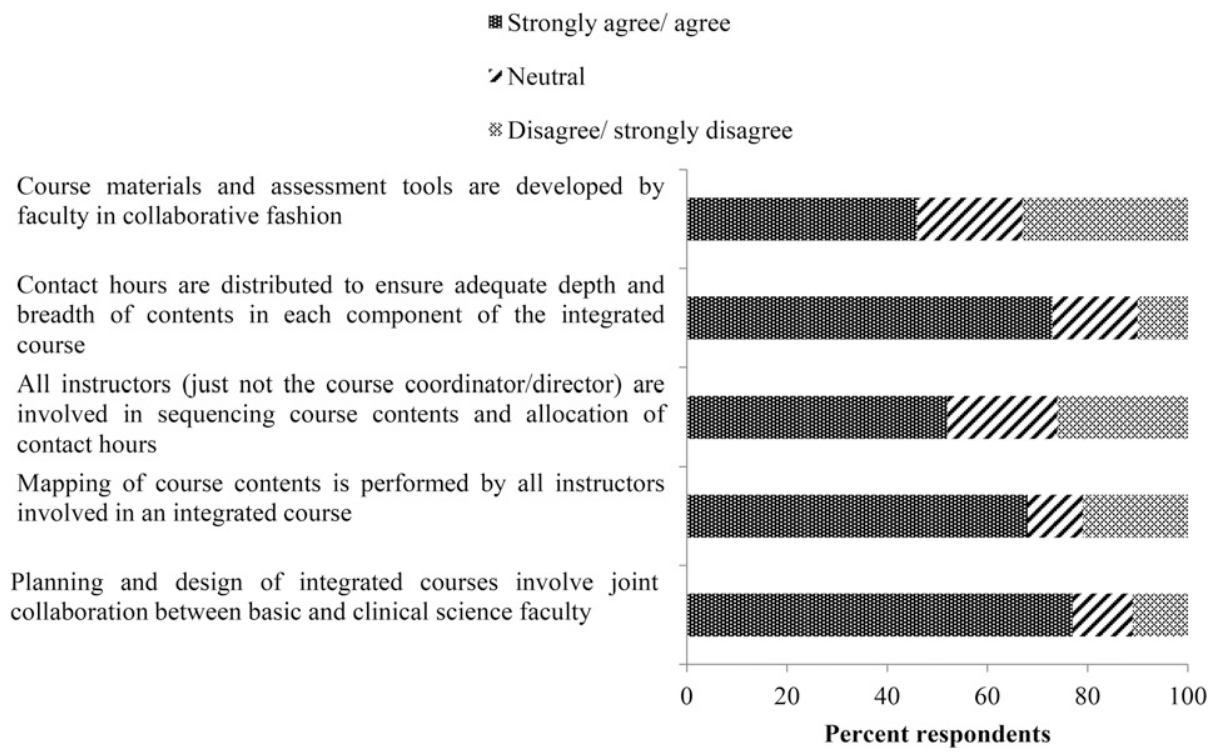

Figure 4. Faculty Perceptions of planning and design of integrated courses 


\section{American Journal of Pharmaceutical Education 2016; 80 (10) Article 166.}

Table 2. Faculty Perceptions of Curricular Integration

\begin{tabular}{|c|c|c|c|c|}
\hline \multirow[b]{2}{*}{ Survey questions } & \multicolumn{3}{|c|}{ Mean response (SD) } & \multirow[b]{2}{*}{$P$ value ${ }^{1}$} \\
\hline & $\begin{array}{l}\text { All institutions } \\
(\mathbf{1 8 3})^{\mathbf{a}}\end{array}$ & Public (80) ${ }^{\mathrm{a}}$ & Private $(104)^{a}$ & \\
\hline \multicolumn{5}{|c|}{ Section A: General perceptions of curricular integration (answered by all survey participants) } \\
\hline $\begin{array}{l}\text { Integration of courses results in learning experiences that } \\
\text { are relevant and engaging while facilitating higher order } \\
\text { learning }\end{array}$ & $4.0 \pm 0.9(181)$ & $4.0 \pm 0.9(79)$ & $3.9 \pm 1.0(102)$ & 0.787 \\
\hline $\begin{array}{l}\text { Integration of basic and clinical sciences forms a framework } \\
\text { of student learning allowing the integration of } \\
\text { knowledge, skills, and attitudes to offer effective patient } \\
\text { care }\end{array}$ & $4.0 \pm 0.9(181)$ & $4.1 \pm 0.8(79)$ & $4.0 \pm 1.0(102)$ & 0.671 \\
\hline $\begin{array}{l}\text { The application, analysis, synthesis, and evaluation of } \\
\text { information are best achieved in an interdisciplinary } \\
\text { integrated course }\end{array}$ & $3.6 \pm 1.0(183)$ & $3.6 \pm 1.0(79)$ & $3.6 \pm 1.1(104)$ & 0.593 \\
\hline $\begin{array}{l}\text { Integrated courses are well-suited for developing problem- } \\
\text { solving skills needed in practice }\end{array}$ & $3.9 \pm 1.0(183)$ & $3.9 \pm 0.9(80)$ & $3.8 \pm 1.0(103)$ & 0.958 \\
\hline \multicolumn{5}{|c|}{$\begin{array}{l}\text { Section B: Development and implementation of integrated courses (answered only by respondents from programs } \\
\text { with integration) }\end{array}$} \\
\hline $\begin{array}{l}\text { Planning and design of integrated courses involve joint } \\
\text { collaboration between basic and clinical science faculty }\end{array}$ & $3.9 \pm 1.1(92)$ & $3.8 \pm 1.1(41)$ & $4.0 \pm 1.0(51)$ & 0.523 \\
\hline $\begin{array}{l}\text { Mapping of course contents is performed by all instructors } \\
\text { involved in an integrated course }\end{array}$ & $3.7 \pm 1.1(94)$ & $3.5 \pm 1.1(41)$ & $3.8 \pm 1.1(52)$ & 0.068 \\
\hline $\begin{array}{l}\text { All instructors (just not the course coordinator/director) are } \\
\text { involved in sequencing course contents and allocation of } \\
\text { contact hours }\end{array}$ & $3.3 \pm 1.1(93)$ & $3.2 \pm 1.0(41)$ & $3.4 \pm 1.2(52)$ & 0.296 \\
\hline $\begin{array}{l}\text { Contact hours are distributed to ensure adequate depth and } \\
\text { breadth of contents in each component of the integrated } \\
\text { course }\end{array}$ & $3.7 \pm 0.9(93)$ & $3.6 \pm 1.0(40)$ & $3.8 \pm 1.0(51)$ & 0.143 \\
\hline $\begin{array}{l}\text { Course materials and assessment tools are developed by } \\
\text { faculty in collaborative fashion }\end{array}$ & $3.0 \pm 1.0(94)$ & $3.0 \pm 1.1(40)$ & $3.2 \pm 1.1(53)$ & 0.202 \\
\hline
\end{tabular}

in implementation of curricular integration that were reported included a lack of consistency in course materials, lack of coordination among respective instructors implementing the course, and the inadequate level of interaction between basic sciences and practice faculty members (identified by $63 \%, 53 \%$, and $60 \%$ respondents, respectively). Fifty-six percent of respondents have specified inadequate support and training of faculty members to execute the integrated model of teaching as another barrier towards curricular integration. Other barriers identified in our study included non-harmonious relationships among departments (eg, pharmaceutical sciences vs practice) and faculty power struggles and territorialism.

Sixty-three open-ended comments from 186 respondents were recorded and subjected to thematic analysis. Three major themes emerged from these comments: challenges and opportunities for successful implementation of integration, positive students' learning experiences, and uncertainty of the outcomes of integrated curriculum (Table 3 ).

\section{DISCUSSION}

The integration of science and practice curricula within pharmacy is crucial in generating graduates capable of applying basic science principles to solve therapeutic problems. ${ }^{23}$ Traditionally, an integrated curriculum is considered to have horizontal and vertical dimensions. ${ }^{24}$ In the context of pharmacy education, horizontal integration occurs among courses that are taught concurrently, such as physiology, pathophysiology, medicinal chemistry, pharmaceutics, pharmacology, and pharmacotherapeutics. Vertical integration refers to the integration of different disciplines taught in different phases of the program. The application of learning experiences to real-world situations represents another aspect of vertical integration. Curricular integration is conceptualized as a continuum with complete disciplinary isolation at 


\section{American Journal of Pharmaceutical Education 2016; 80 (10) Article 166.}

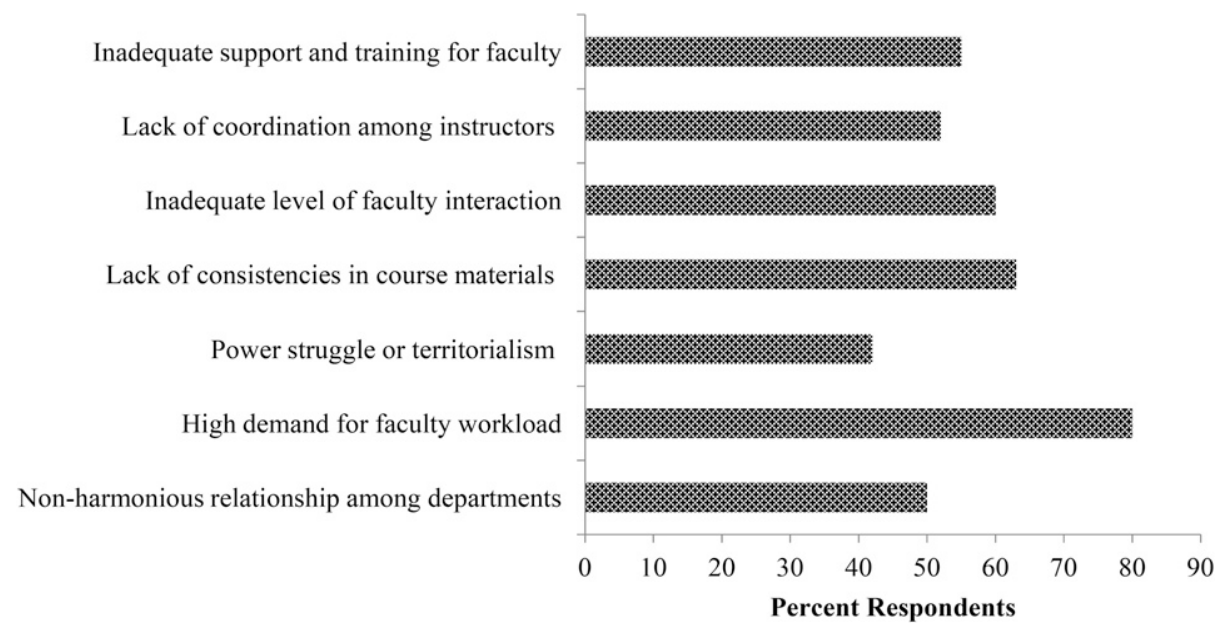

Figure 5. Barriers and challenges to implementation of integrated courses

one end and a fused strategy (fully integrated) at the other where disciplinary identities are lost and curriculum spins around real-life experiences. Several intermediate approaches where progressively higher levels of connections are made have been described by Harden. ${ }^{25}$

This study provides the current status of integration of basic and clinical science courses in US pharmacy programs. The forms of horizontal integration between basic and clinical science courses varied widely. The most common form of integration adopted by pharmacy programs involved the coordinated approach of delivery. This coordinated approach to teaching may represent different levels of integration such as temporal coordination, sharing, correlation, and complementarity based on Harden's "integration ladder." ${ }^{25}$ In temporal coordination, similar course content is taught at the same time while the overall content of courses remains discipline-specific. However, in this model, students are left to make linkages among learned ideas. The sharing, correlation, and complementary approach of teaching strategies offers a higher level of integration than temporal coordination while keeping discipline-specific autonomy intact. Our survey findings suggest that about two-thirds of pharmacy programs have integration that is well-aligned with the aforementioned steps of the "integration ladder."

In the multidisciplinary integration model, contents from different disciplines are merged based on a theme, topic, or issues. ${ }^{25}$ An ideal example of multidisciplinary integration in healthcare education is the teaching approach where modules/courses are organized around an organ/body system. ${ }^{13,26}$ Contents from physiology, pathophysiology, pharmacology, and therapeutic areas constitute the theme or problem that is the focus for students' learning. ${ }^{27}$ In multidisciplinary integration, the problem or theme is viewed through the lens of disciplines and the disciplines preserve their identity. ${ }^{25}$ The interdisciplinary approach affords a higher level of integration where disciplinary contents are combined in a new course, and disciplinary identity is lost. ${ }^{25}$

Our survey identified 25 programs that merge contents from basic and clinical science based on a disease state or organ system. Moreover, these courses were reportedly taught in a single session by multiple faculty members. These programs incorporated integrated cases in addition to integrated lecture. While some might suggest these programmatic changes represent interdisciplinary integration, it is not possible to be definitive about such an assertion as the loss of discipline identity was not investigated in the survey. Nonetheless, 25 programs have implemented one of the highest levels of integration (ie, multi- or interdisciplinary), accounting for $22 \%$ of the 112 responding programs.

Greater faculty efforts are of paramount importance in implementing integration in the program, course, and individual classroom session-level as described by Goldman and Schroth. ${ }^{28}$ At the programmatic level, the planning of integrated courses, course placements, and sequences in the curriculum should be addressed along with the associated resource implications. At the course level, strong collaboration, teamwork, and open communication among faculty members are critical to the development and success of course objectives, contents, sequencing, contact hour allocation, and assessment. In the classroom session-level, faculty members must illustrate the linkages and relevance among disciplines, include integrated activities (eg, cases, assignments, projects), and incorporate integrated assessments. 


\section{American Journal of Pharmaceutical Education 2016; 80 (10) Article 166.}

Table 3. Thematic Analysis of Respondents' Open-ended Comments on Integration of Basic and Clinical Science Courses

\begin{tabular}{|c|c|c|}
\hline Major Themes & Representative comments & Citations \\
\hline $\begin{array}{l}\text { Positive learning } \\
\text { experiences }\end{array}$ & $\begin{array}{l}\text { "I think curricular integration helps students see the big picture and make relevant } \\
\text { and necessary connections." } \\
\text { "I believe curricular integration is a positive step in improving the learning } \\
\text { experience for students." } \\
\text { "The integration is however necessary since application of basic science is what } \\
\text { a future pharmacist needs to apply in his/her practice site regardless whether in a } \\
\text { hospital, retail pharmacy, or somewhere else practicing pharmacy." } \\
\text { "I think integrated course will also facilitate learning and may increase the chance of } \\
\text { retaining the information for a long time since they see the practice of it } \\
\text { immediately." }\end{array}$ & 11 \\
\hline $\begin{array}{l}\text { Challenges and } \\
\text { opportunities for } \\
\text { successful } \\
\text { implementation } \\
\text { of integration }\end{array}$ & $\begin{array}{l}\text { "Integration of the courses/topics is very difficult and can result in a "mini-silo" effect } \\
\text { where the faculty members go in and teach their little area without respect to the } \\
\text { other aspects being taught. It is a very difficult task to fully integrate the } \\
\text { subject material." } \\
\text { "... but cooperation is necessary between basic science and clinical faculty to } \\
\text { coordinate content in a unified way." } \\
\text { "There needs to be adequate communication between the course coordinator and } \\
\text { the lecturers before, during, and after each course offering to make it a success." } \\
\text { It should be a continual work-in-progress, not a one-time venture. } \\
\text { "Need an effective leader to keep it going. As we get better at addressing issues } \\
\text { and getting the barriers out of the way, the focus will truly be on the student } \\
\text { and their learning, which I sincerely believe will make them stronger and } \\
\text { well-prepared for rotations and real-life situations." }\end{array}$ & 15 \\
\hline $\begin{array}{l}\text { Skeptical about the } \\
\text { positive outcomes } \\
\text { of integration }\end{array}$ & $\begin{array}{l}\text { "Full integration, however, is not practical. When everything is integrated, some of the } \\
\text { contents get lost. Additionally, there are no references for faculty to review. } \\
\text { Hence, it is like writing a new book!" } \\
\text { "Essentially full integration is turning pharmacy education into a vocational school." } \\
\text { "We are not convinced it provides the best model for delivery of content and given } \\
\text { our assessment and licensure results coupled with residency and employment } \\
\text { placement our current model would seem to work well." } \\
\text { "Our faculty do not believe that integration between the basic sciences and } \\
\text { therapeutics leads to better learning outcomes." }\end{array}$ & 11 \\
\hline $\begin{array}{l}\text { Disadvantages of } \\
\text { curricular integration }\end{array}$ & $\begin{array}{l}\text { "Total integration dilutes content such that we are training students to perform one } \\
\text { step above a pharmacy technician - perhaps a pharmacy technologist." } \\
\text { "...In addition, overarching concepts in these disciplines were not appreciated by the } \\
\text { students because of the fragmented presentation of material." } \\
\text { "Medicinal chemistry and toxicology became marginalized due to their small } \\
\text { contribution on assessments relative to the other disciplines." }\end{array}$ & 5 \\
\hline
\end{tabular}

As evidenced by our study results, opportunities exist to improve faculty collaboration and joint efforts towards achieving meaningful curricular integration in US pharmacy programs. Although $76 \%$ of the respondents agreed or strongly agreed that the planning and design of integrated courses involved collaboration between basic and clinical science faculty members, agreement was fairly low (51\%) regarding team efforts necessary for sequencing of contents, contact hour distribution, development of course materials, and assessment tools. While curriculum design and structure are foundational to integration, imple- mentation by faculty members is the key to successful integration. $^{29}$

Our study revealed that diverse teaching methodologies are used in delivering integrated courses. Case-based teaching and team-based learning formats are effective approaches to teaching. ${ }^{11,30}$ Several studies describe problem-based learning (PBL) as an additional means of teaching integrated basic and clinical science courses. ${ }^{31-}$

${ }^{33}$ One might argue that the diversity of delivery methods used in PBL could potentially impact integration. ${ }^{34}$ However, curriculum evaluation studies have suggested that 


\section{American Journal of Pharmaceutical Education 2016; 80 (10) Article 166.}

content and assessment rather than the delivery method (eg, PBL) used, are the deciding factors for successful integration. $^{35,36}$

Assessment, in an integrated manner, is an often underappreciated component of curriculum integration. While faculty members "set the table" for integration, from a learning standpoint, the learner ultimately needs to integrate his or her own knowledge and experience. The same level of collaboration required to create and deliver an integrated session, course, or curriculum, is also necessary to assess whether integrated learning has indeed taken place in the mind of the student. While the importance of integrated assessment may be apparent, most of the available literature is descriptive rather than evaluative and focuses on the design and development of integrated curricula and learner's perception of integration rather than on whether actual learning has been achieved. This paucity of data on the assessment of integrated learning may be due to the inherent complexities of curricular integration. The learning expectations for students in an integrated course or curriculum are beyond the mastery of disciplinary knowledge or skills. In the context of pharmacy education, the outcome measures should reflect students' sophisticated understanding of how basic sciences relate to clinical practice.

Therefore, the assessment of an integrated course or curriculum includes a students' ability to form connections between contents across disciplines; transfer knowledge, skills, and abilities gained in one context to another; and bridge academic knowledge and life experiences. Several assessment and evaluation strategies such as use of multiple-choice questions based on patient scenarios focusing contents from different disciplines, reflection questions, short or long essay questions, projects, assignments, case studies, etc, have been suggested in the literature. ${ }^{4,37}$ Additional data are necessary to assess whether integrated learning is indeed taking place in the minds of the learners. Integrated assessment may already be taking place; however, it has not been well documented in the pharmacy literature. To this end, the authors are in the process of developing a survey instrument to assess integration in US pharmacy programs.

The need to acquire data to assess integrated learning and improved outcomes is often cited by the critics of curriculum integration. ${ }^{20}$ While there is limited empirical research to prove the benefits of integrated curricula within healthcare education, there is evidence that integration creates relevance and meaning for new learning, improves retention of fundamental information, and allows students to apply learned knowledge in real-life situations. ${ }^{15-17}$ Several studies have provided evidence for the benefit of linking clinical concepts to underlying basic science concepts. Integration leads to deep understanding and application of basic science principles in the appropriate clinical context. ${ }^{38-40}$ A series of studies demonstrated that students who were taught pathology in an integrated approach that linked physiology to clinical pathology were better able to diagnose difficult clinical cases. ${ }^{17,41,42}$

Even with the aforementioned benefits, curricular integration has been an enduring challenge for health professions education. ${ }^{25}$ The move from traditional subjectbased to an integrated curriculum requires a substantive curricular change. ${ }^{29}$ Our study revealed a number of challenges and obstacles to curriculum integration among which were high demand for faculty workload, inadequate faculty support and training, and inadequate level of faculty interaction to name a few. An important yet less-discussed barrier includes crossing disciplinary boundaries.

With any discipline, an inner logic and distinct view of knowledge, expectations, and pedagogical practice exist. $^{43,44}$ These complex disciplinary differences complicate the process of crossing disciplinary boundaries in an integrated curriculum. There are also arguments that integrated curricula are created at the expense of disciplinary depth and the resulting content dilution contributes to superficial learning. ${ }^{45}$ In medical education, how to structure and balance an integrated curriculum in the absence of adequate direction has been a challenge. ${ }^{46}$ True integration demands that foundational sciences throughout the curriculum are maintained and reinforced. ${ }^{37,47}$ Considerable collaborative efforts, faculty appreciation, understanding of the linkages between disciplines, careful and contextual selection of disciplinary depth and breadth all contribute to the development of a balanced integrated curriculum. ${ }^{28,37,47-49}$

The response to our survey questions reflects the diversity of integration models documented in the literature. As suggested by Harden, moving up the "integration ladder" to achieve higher levels of integration requires a team of faculty members to develop course objectives, content, sequencing, and contact hour allocation, as well as integrated forms of assessment. As evidenced by our study results, opportunities exist to improve faculty collaboration and joint efforts towards achieving meaningful curricular integration. While the root causes of barriers are multi-factorial and complex in nature, the following suggestions may afford opportunities to mitigate some of challenges: It is crucial that the dean, associate and assistant deans, as well as department chairs, are fully committed to and involved with the role and value of integration should curricular integration be the goal; the 


\section{American Journal of Pharmaceutical Education 2016; 80 (10) Article 166.}

buy-in of members of the curriculum committee is instrumental in creating a framework and structure for curricular integration; a school or college's investment in identifying and nurturing faculty champions for curricular integration plays an invaluable role in engaging faculty at-large in the process; and considering that higher levels of integration require significant time commitment, support such as protected time, detailed workload analyses, additional staff support, and possibly tools may be necessary. Lastly, continuous faculty development in the area of curricular integration may also be essential for successful implementation.

There are several limitations to the current study. While the number of PharmD programs responding to our survey was high, in many cases, only one faculty member from a given program reported his/her perceptions of curricular integration. Realizing that integration involves multiple faculty members, responses from only one person may not accurately reflect the views of other team members involved with integration in a given program. Although not inquired about in the survey, understanding the extent of involvement that the respondent had in the integrated courses may have further strengthened the validity of their views and perceptions of integration. Another limitation of our study was coding and theme generation from the 63 open-ended comments received. While 42 comments were coded into three major themes, the remaining comments were too vague, unrelated, or contained factual information that could not be coded.

\section{CONCLUSION}

The survey results described herein suggest wide variations in the design and implementation of integrated courses among US programs of pharmacy. Even among integrated courses, opportunities for additional collaborative efforts remain. The outcomes and assessment of curricular integration in US colleges and pharmacy remain to be determined.

\section{ACKNOWLEDGMENT}

The authors would like to thank Drs. Kyle Sousa and Fred Farris for critically reading the manuscript.

\section{REFERENCES}

1. Wartman S, Davis A, Wilson M, Kahn N, Sherwood R, Norwalk A. Curricular change: recommendations from a national perspective. Acad Med. 2001;76(4 Suppl):S140-S145.

2. Irby DM, Cooke M, O'Brien BC. Calls for reform of medical education by the Carnegie Foundation for the Advancement of Teaching: 1910 and 2010. Acad Med. 2010;85(2):220-227.

3. Jacobs HH. Interdisciplinary Curriculum:Design and Implementation. Alexandria, VA: Association for Supervision and Curriculum Development; 1989.
4. Husband AK, Todd A, Fulton J. Integrating science and practice in pharmacy curricula. Am J Pharm Educ. 2014;78(3):Article 63. 5. Anderson MB, Kanter SL. Medical education in the United States and Canada, 2010. Acad Med. 2010;85(9 Suppl):S2-S18.

6. Haden NK, Hendricson WD, Kassebaum DK, et al. Curriculum change in dental education, 2003-09. J Dent Educ. 2010;74(5):539557.

7. Accreditation Council for Pharmacy Education. Accreditation standards and key elements for the professional program in pharmacy leading to the doctor of pharmacy degree. Standards 2016. https:// www.acpe-accredit.org/pdf/Standards2016FINAL.pdf. Accessed October 27, 2015.

8. Albano CB, Brown W. Integration of physical assessment within a pathophysiology course for pharmacy. Am J Pharm Educ. 2012;76 (1):Article 14.

9. Stewart AL, Buckner IS, Wildfong PL. A shared assignment to integrate pharmaceutics and pharmacy practice course concepts. Am $J$ Pharm Educ. 2011;75(3):Article 44.

10. Kullgren J, Radhakrishnan R, Unni E, Hanson E. An integrated course in pain management and palliative care bridging the basic sciences and pharmacy practice. Am J Pharm Educ. 2013;77(6): Article 121.

11. Kolluru S, Roesch DM, Akhtar de la Fuente A. A multiinstructor, team-based, active-learning exercise to integrate basic and clinical sciences content. Am J Pharm Educ. 2012;76(2):Article 33.

12. Karimi R, Arendt CS, Cawley P, Buhler AV, Elbarbry F, Roberts SC. Learning bridge: curricular integration of didactic and experiential education. Am J Pharm Educ. 2010;74(3):Article 48. 13. Islam MA, Schweiger TA. Students' perception of an integrated approach of teaching entire sequence of medicinal chemistry, pharmacology, and pharmacotherapeutics courses in PharmD curriculum. J Pharm Pract. 2015;28(2):220-226.

14. Nelson M, Allison SD, McCollum M, et al. The Regis Model for pharmacy education: a highly integrated curriculum delivered by Team-Based Learning (TBL). Curr Pharm Teach Learn. 2013;5(6): 555-563.

15. Woods NN, Brooks LR, Norman GR. It all makes sense: biomedical knowledge, causal connections and memory in the novice diagnostician. Adv Health Sci Educ Theory Pract. 2007;12(4):405415.

16. Thistlethwaite JE, Davies D, Ekeocha S, et al. The effectiveness of case-based learning in health professional education. A BEME systematic review: BEME Guide No. 23. Med Teach. 2012;34(6): e421-e444.

17. Woods NN, Brooks LR, Norman GR. The value of basic science in clinical diagnosis: creating coherence among signs and symptoms. Med Educ. 2005;39(1):107-112.

18. Klein JT. Integrative learning and interdisciplinary studies. peerReview. 2005;7(4):8-10.

19. Boudreau JD, Cassell EJ. Abraham Flexner's "mooted question" and the story of integration. Acad Med. 2010;85(2):378-383.

20. Pearson ML, Hubball HT. Curricular integration in pharmacy education. Am J Pharm Educ. 2012;76(10):Article 204.

21. Braun V, Clarke V. Using thematc analysis in psychology. Qual Res Psychol. 2006;3(2):77-101.

22. Regions and Divisions. US Census Bureau. http://www.census. gov/econ/census/help/geography/regions_and_divisions.html. Accessed August 11, 2015.

23. Ratka A. Integration as a paramount educational strategy in academic pharmacy. Am J Pharm Educ. 2012;76(2):Article 19. 


\section{American Journal of Pharmaceutical Education 2016; 80 (10) Article 166.}

24. Benor DE. Interdisciplinary integration in medical education: theory and method. Med Educ. 1982;16(6):355-361.

25. Harden RM. The integration ladder: a tool for curriculum planning and evaluation. Med Educ. 2000;34(7):551-557.

26. Davis MH, Harden RM. Planning and implementing an undergraduate medical curriculum: the lessons learned. Med Teach. 2003;25(6):596-608.

27. Irby DM, Wilkerson L. Educational innovations in academic medicine and environmental trends. J Gen Intern Med. 2003;18(5): 370-376.

28. Goldman E, Schroth WS. Perspective: deconstructing integration: a framework for the rational application of integration as a guiding curricular strategy. Acad Med. 2012;87(6):729-734. 29. Hopkins R, Pratt D, Bowen JL, Regehr G. Integrating basic science without integrating basic scientists: reconsidering the place of individual teachers in curriculum reform. Acad Med. 2015;90(2):149153.

30. Bowe CM, Voss J, Thomas Aretz H. Case method teaching: an effective approach to integrate the basic and clinical sciences in the preclinical medical curriculum. Med Teach. 2009;31(9):834-841.

31. Clough RW, Shea SL, Hamilton WR, et al. Weaving basic and social sciences into a case-based, clinically oriented medical curriculum: one school's approach. Acad Med. 2004;79(11):10731083.

32. Minhas PS, Ghosh A, Swanzy L. The effects of passive and active learning on student preference and performance in an undergraduate basic science course. Anat Sci Educ. 2012;5(4):200207.

33. Callis AN, McCann AL, Schneiderman ED, Babler WJ, Lacy ES, Hale DS. Application of basic science to clinical problems:

traditional vs. hybrid problem-based learning. J Dent Educ. 2010;74 (10):1113-1124.

34. Neville AJ. Problem-based learning and medical education forty years on. A review of its effects on knowledge and clinical performance. Med Princ Pract. 2009;18(1):1-9.

35. Schmidt HG, Machiels-Bongaerts M, Hermans H, ten Cate TJ, Venekamp R, Boshuizen HP. The development of diagnostic competence: comparison of a problem-based, an integrated, and a conventional medical curriculum. Acad Med. 1996;71(6):658664.
36. Nouns Z, Schauber S, Witt C, Kingreen H, Schüttpelz-Brauns K. Development of knowledge in basic sciences: a comparison of two medical curricula. Med Educ. 2012;46(12):1206-1214.

37. Brauer DG, Ferguson KJ. The integrated curriculum in medical education: AMEE Guide No. 96. Med Teach. 2015;37(4):312-322.

38. Goldszmidt M, Minda JP, Devantier SL, Skye AL, Woods NN. Expanding the basic science debate: the role of physics knowledge in interpreting clinical findings. Adv Health Sci Educ Theory Pract. 2012;17(4):547-555.

39. Balla JI, Biggs JB, Gibson M, Chang AM. The application of basic science concepts to clinical problem-solving. Med Educ. 1990;24(2):137-147.

40. Vadivelu J. Evaluation of basic science knowledge retention in clinical teaching. Med Educ. 2008;42(5):520-521.

41. Woods NN, Brooks LR, Norman GR. The role of biomedical knowledge in diagnosis of difficult clinical cases. Adv Health Sci Educ Theory Pract. 2007;12(4):417-426.

42. Woods NN, Neville AJ, Levinson AJ, Howey EH, Oczkowski WJ, Norman GR. The value of basic science in clinical diagnosis. Acad Med. 2006;81(10 Suppl):S124-S127.

43. Entwistle NJ. Teaching for Understanding at University: Deep Approaches and Distinctive Ways of Thinking. New York, NY: Palgrave Macmillan; 2009.

44. Becher T, Trowler PR. Academic Tribes and Territories: Intellectual Enquiry and The Culture of Disciplines. 2nd ed. Philadelphia, PA: Open University Press; 2001.

45. Smith SR. Toward an integrated medical curriculum. Med Health R I. 2005;88(8):258-261.

46. General Medical Council. Tomorrow's Doctors. Outcomes and Standards for Undergraduate Medical Education. London, UK: GMC; 2009.

47. Spencer AL, Brosenitsch T, Levine AS, Kanter SL. Back to the basic sciences: an innovative approach to teaching senior medical students how best to integrate basic science and clinical medicine. Acad Med. 2008;83(7):662-669.

48. Wilkerson L, Stevens CM, Krasne S. No content without context: integrating basic, clinical, and social sciences in a pre-clerkship curriculum. Med Teach. 2009;31(9):812-821.

49. Haramati A. Educating the educators: a key to curricular integration. Acad Med. 2015;90(2):133-135. 